\title{
Help-seeking trajectory in patients with rheumatoid arthritis
}

\author{
Ingris Pelaez $^{1} \cdot$ Claudia Infante $^{2} \cdot$ Rosana $_{\text {Quintana }}{ }^{3}$
}

Received: 23 March 2015 /Revised: 10 April 2015 / Accepted: 17 May 2015 / Published online: 23 July 2015

(C) The Author(s) 2015. This article is published with open access at Springerlink.com

\begin{abstract}
Early diagnosis and treatment of rheumatoid arthritis (RA) depends on the degree of fit between the characteristics of the patients and those of the health services. Ensuring timely assessment and treatment is the ideal medical care of RA. The reasons that underlay delays and the help-seeking trajectories are contextually determined. This study aims to identify the empirical evidence related to the help-seeking process and delay in RA in Latin America and to create a comprehensive model integrating the RA medical care processes of help-seeking and delay in a mixed health care system with variable accessibility. Non-systematic literature review of studies with both quantitative and qualitative methodology was conducted. Most of the research about delay and its associated variables have been undertaken in European countries and with White population and cannot be translated to the Latin America context where this research is almost inexistent. These countries have a completely different social context, and for most of the population, the health services are insufficient, inaccessible, fragmented, limited, and inequitable. Our results also show that in RA medical care utilization research, the theories and measurements of the constructs of illness trajectories, help-seeking, and accessibility are not integrated. We offer a conceptual framework that integrates help-seeking trajectories, delay, and accessibility of RA
\end{abstract}

Claudia Infante

claudiainfante@prodigy.net.mx

1 Rheumatology Service, General Hospital of Mexico, Mexico City, Mexico

2 Institute for Social Research, UNAM, National Autonomous University of Mexico, Circuito Mario de la Cueva S/N, Ciudad Universitaria, C.P. 04510 Mexico City, Mexico

3 Provincial Hospital of Rosario, Rosario, Santa Fe, Argentina medical health services. If research on RA service utilization is to be undertaken in these countries, there is a need for a comprehensive framework than can enable researchers to integrate and contextualize the study of the problems within broad theoretical and methodological perspectives.

Keywords Accessibility · Delay $\cdot$ Health care system . Help-seeking · Illness trajectory · Latin American · Rheumatoid arthritis

\section{Introduction}

Early diagnosis and treatment of rheumatoid arthritis (RA) depends on the degree of fit between the characteristics of the patients and those of the health services. It has been broadly demonstrated that a treatment delay of more than 3 months increases the risk of adverse outcomes [1-7]. In turn, these outcomes are related to devastating impacts on the individual and at different social levels. Research on the factors involved in the delayed seeking of medical attention is highly warranted. Most of the research about delay and its associated variables has been undertaken in European countries and Canada and with White population [8-15].

Research on delay and medical care utilization of RA is almost inexistent in Latin America. Most of the existing research results documenting the problems of delay, helpseeking process, and medical care cannot be translated to developing countries because they describe problems grounded in local social and health system contexts. The complexity of these factors in Latin America is bound to have an important impact on adequate medical care in RA. Efforts directed to the encouragement of the scientific documentation of these problems in Latin America (LA) are needed. 
In order to facilitate the translation and utilization of the existing knowledge about timely and adequate medical treatment of RA into the Latin American context, we need to analyze the literature evidences in the light of their relevance for the local circumstances. The development of a comprehensive conceptual framework aimed to increase understanding of the contextual determinants of the study of the relationship between the different concepts of health care involved can help to map the common or specific characteristics of the research to be undertaken.

\section{Concepts}

\section{Help-seeking process}

The help-seeking career has been defined as "a sequence of stages typically passed through by an individual with some real or perceived problem who is on the way to formal treatment, rehabilitation, or perhaps death" [16]. Behavior towards illness and help-seeking are among the most widely used concepts in medical sociology. These concepts range from the initial perception of symptoms, including all relevant experiences and subsequent actions of the patient towards the disease and their coping strategies. Help-seeking includes the need for all kinds of support, medical and nonmedical, to cope with the disease over the so-called illness trajectory [17].

\section{Illness trajectory}

The concept of illness goes beyond the biomedical terms of signs, symptoms, and diseases and refers to the cultural dimensions of the disease, particularly to the semiotic (how meaning is created) and phenomenological construction of the symptoms and other forms of expression. Illness is the way that the individuals suffer the alterations of their health in accordance with their biological, psychological, and sociocultural individuality [18].

The experience of the illness comprises the perception by the subjects of the progress of their affliction through time and actions undertaken to confront it [19]. The lived experience of illness over time makes illness trajectories.

Strauss and Glaser [20] coined the term "illness trajectory" to refer "not only to the physiological unfolding of a patient's disease but to the total organization of work done over that course, plus the impact on those involved with that work and its organization." This concept revolves around the perception of the patients and considers the impact of the disease on them, together with the responses generated in the course of seeking medical care [20].

Despite the growing body of empirical work devoted to the study of adequate medical care for RA, scientific theory on the integration of social and clinical evidences into a comprehensive model of caring trajectories for the analysis these processes in Latin American context remains underdeveloped [21]. Based on the examination of selected publications on medical care delay, the help-seeking process, and accessibility of RA, this paper is an attempt to begin to address this gap.

\section{Objectives}

1. To identify all qualitative and quantitative research related to help-seeking process and delay in RA medical care in Latin America.

2. To review relevant literature on help-seeking process and delay in RA.

3. To create a comprehensive model integrating the RA medical care processes of help-seeking and delay in a mixed health care system with variable accessibility.

\section{Material and methods}

Non-systematic literature review of studies with both quantitative and qualitative methodology was conducted. Methodological phases proposed by Greenhalgh [22] were followed:

1. Planning phase: The objective was to assemble a multidisciplinary research team (rheumatologist, medical sociologist, and anthropologist) and to define the research questions for the development of the review.

2. Search phase: The search was conducted in the databases: MEDLINE, EMBASE, LILACS, SOCIAL SCIENCE INDEX, and PSYCOINFO. The key words were helpseeking behavior, rheumatoid arthritis, and delay. We also did hand searches in key Latin American rheumatology journals, books, and theses. The search included qualitative and quantitative studies published in English or Spanish.

3. Mapping phase: In this phase, the key elements of the selected studies (conceptual, theoretical, methodological, and instrumental) were identified and articles meeting the inclusion criteria were reviewed.

4. Synthesis phase: Data relevant to the objectives of this study were synthesized using interpretive synthesis strategy.

5. Recommendation phase: The construction of a conceptual framework of RA patients for LA (Fig. 1).

\section{Results}

Our findings fall into two categories: (1) illness trajectories based on qualitative synthesis, (2) summary and analysis of quantitative studies. 
Fig. 1 Methods of review. Greenhalgh [22]

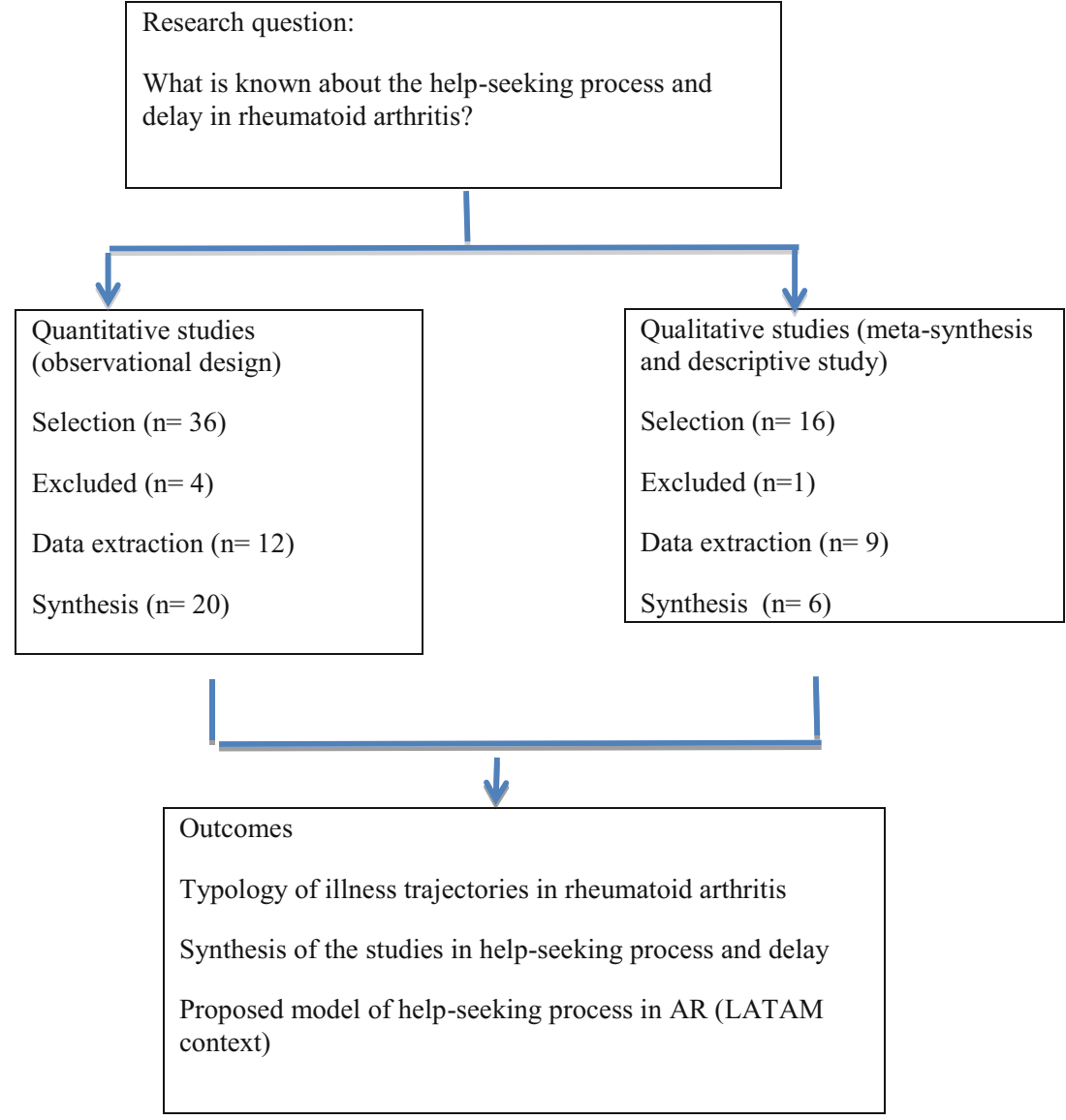

\section{Illness trajectories based on qualitative synthesis}

The empirical findings of the research on help-seeking in RA patients that are documented in the literature confirm the three main types of trajectories for RA proposed by Glasser and Strauss [20]. These trajectories only include the "pre-patient phase" as they begin with the symptom discovery and end when medical care is initiated. Figure 2 depicts a chronological organization (left to right) of the most relevant elements of the three trajectories: Trajectory 1 at top, trajectory 2 at the middle, and trajectory 3 at the bottom (with thick lines). The first element of the trajectories is at the left and includes the symptoms, the type of onset, their intensity, and duration. The way that the illness is experienced within a cultural context (at the left of the figure) as well as the knowledge, beliefs, and attributions (at the top) determine the interplay and pace of following actions graphically summarized in the central and right part of the diagram. The interactions between the experience of illness and the internal reactions of the individual are illustrated in the shadowed box at the middle of the figure (e.g., normalizing, minimizing, adaptation, credibility). Seeking help from the social network takes place all along the trajectory and can delay or facilitate early medical consultation. Lay consultation can begin since the initial perception of the first symptoms in any of the three types of trajectories. Subsequent actions are at the right side of the figure and can range from taking no action to a rapid search for medical consultation. Self-medication, the use of folk or alternative treatments, and seeking information are shown in the figure before seeking medical attention because they have frequently been mentioned as actions that delay the first medical consultation. However, these behaviors can take place at any time: before or after the initiation of formal medical care.

The three trajectories have the following characteristics:

1. The stable illness trajectories. The disease is present but is not perceived as such. The symptoms are insidious (gradual), with mild pain due to inflammation. There is no initial impact on daily life activities and there is a minimization of symptoms attributable to quotidian life matters, e.g., old age or type of work. As symptoms are not considered serious, they are normalized [11, 23-25].

2. The oscillating trajectories. The disease fluctuates between phases of activity and improvement until the persistence of the symptoms produces disability. The behavior of the individuals is to "wait and see." Patient minimizes the severity of the disease and experiences uncertainty and distress. This leads to the use of alternative or 


\section{RA Trajectories of help-seeking at the pre-patient phase}

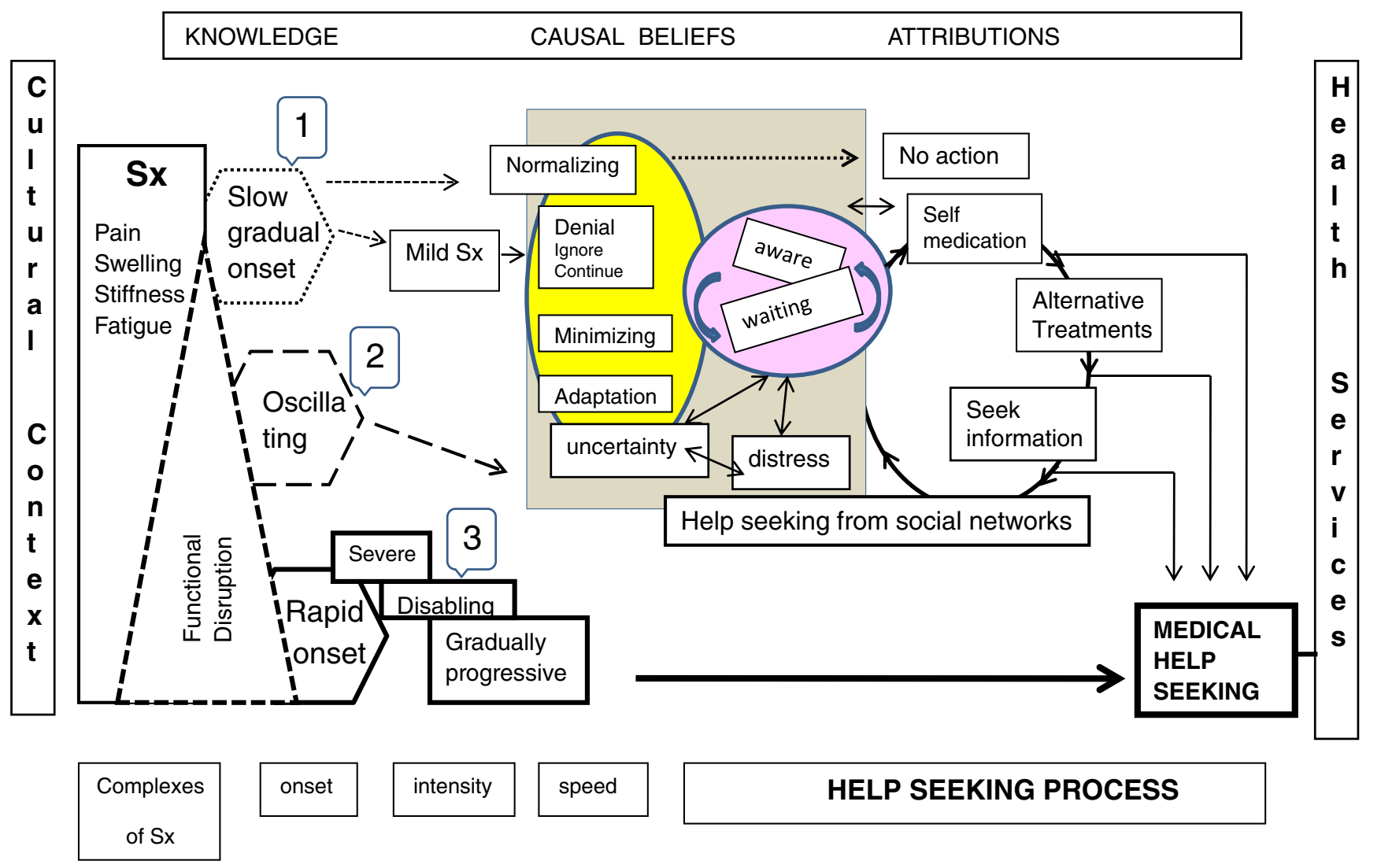

Fig. 2 RA trajectories of help-seeking at the pre-patient phase

folk treatments and prompts to seek information and advice from the social network. This trajectory is characterized by having "good days and bad days" [11, 23-25].

3. The deteriorating trajectories. Impairment predominates over improvement. Symptoms manifest abruptly, accompanied by increased severity and duration of pain and swelling. The affection of small joints, morning stiffness, and fatigue lead to a significant functional impairment, with an impact on everyday life, emotions, work routine, and family interactions. Even though the patients do not have a favorable response to self-care, they "get used" to pain, but it interferes with their work and daily activities [11, 23-26].

The trajectories 1 and 2 (slow or vague/transitory symptoms) are the ones where patient-related delay has been more commonly found. Symptoms are normalized or not seen as related with RA [27]. In trajectory 3 (rapid onset), the severe pain and the functional impairment accelerate seeking medical attention.

\section{Summary and analysis of quantitative studies}

The literature on medical care in RA places a special emphasis on analyzing the delay in medical help-seeking and the associated variables. However, no quantitative studies have been found in literature measuring the process of helpseeking or accessibility to health care services.

The articles distinguish between three types of delay: patient delay, general practitioner (GP) or primary care physicians (PCP) delay, and delay attributable to hospital or specialist care. The latter is further subdivided into delayed diagnosis and delay within the specialist treatment. Further subdivisions are found in the articles but they do not seem to have been found relevant $[2,4,7,9,12,13,15]$.

The quantitative studies reviewed highlighted patient delay and provider or specialist care-related delay. Most studies were conducted in European or North American countries, except for one carried out in Venezuela. No specific studies addressed the systematic study of RA health care accessibility $[11,13,15,28]$.

A decrease in delay time has been documented. Irvine et al. [8] in 1999 noted that the referral periods from a provider to a rheumatologist significantly shortened over a decade. Raza et al. [13] reported in 2011 a variance in delay across several European countries regarding referral to the specialist care, notably if the primary provider had been an orthopedist.

In 2010, van der Linden et al. [2] published a study in which only $31 \%$ of patients sought specialist care before 
12 weeks since symptoms onset. According to the article, the main patient-related variables were perception and presentation of symptoms and their impact on everyday life, especially in the workplace. Some studies highlight social barriers to health service utilization such as a low socioeconomic status, living in a rural area, and geographic accessibility $[3,7,9,15$, $29,30]$. Gender was another factor associated with delay, e.g., there was a larger delay in referral from GPs in female patients $[6,11]$. There are also findings that show that the delay was larger when patients were seen by a male physician [6].

In a comparison of service utilization in RA patients from different ethnic groups in a UK city, Kumar et al. [31] also highlights the importance of the cultural background in the help-seeking behavior of a population with the same health service availability. Patient delay was longer in South Asian patients compared with other group. They proposed that these patients' views of the symptoms "strongly influenced their behavior in response to them."

Other variables found to be associated to medical care delay were related to primary care and delayed referrals to a specialist. As part of an effort to improve the early diagnosis, the results of an intervention in health services with the implementation of early health care clinics in RA are reported. The result was a decrease in delayed medical care for RA [4].

In most health care systems, PCP acts as the gatekeeper. PCP's clinical competence for the initial diagnosis is important and is directly related to the delay, continuity, and quality of care. PCP is the one that makes a preliminary diagnosis and refers the patient to the rheumatologist. Relevant studies have revealed differences in diagnostic concordance of RA $[32,33]$.

When reviewing available data concerning Latin America, we found only one specific study of the delay in a hospital population of Venezuela. Polanco-Rodriguez et al. [34] found the mean between the types of delay to be ranging from 40.5 to 69.7 months (Table 1). The variables associated with the delay were as follows: female, old age, lower education and socioeconomic level, initial examination by an orthopedist, and using public health care services. Over $75 \%$ exhibited erosions in the first 2 years. Another study of poor Hispanic population in Texas reported a delay of 6.9 years from the onset of symptoms to diagnosis [30] (Table 1).

Studies published in Latin America shed some light, albeit indirectly, on the problem of delay. Massardo et al. [35] found a mean delay of 6 years at the moment of the first visit in patients of a private university hospital in Chile. Public hospital patients had a shorter time lag between the onset of symptoms to the date of the first consultation (3 years) and the patients also had fewer years of formal education. The authors suggest that the difference in time lag from disease onset to the first consultation could have been due to the local patterns of referral. In 2012, Acevedo Vásquez [36] reported in Peru a delay in the diagnosis of RA of $2.29 \pm 5.24$ years in patients seen within the social security system.
In 2001, Kaliski et al. [37] published a study on RA in Mapuche aborigines in Chile. One hundred and six patients from a public specialist hospital were included, most of them $(87.7 \%)$ from rural areas. The mean delay in diagnosis was 4.4 years, $46.9 \%$ had functional class III/IV at the beginning.

A study looked at social and demographic characteristics of RA patients in the province of Córdoba, Argentina, by administering a questionnaire to patients who accessed to the health care services, both public and private. They found that the diagnosis was made later in men; $39.1 \%$ had fewer than 5 years of evolution of the disease, $37.5 \%$ were attending to a public hospital; $80 \%$ were from urban areas. Only $29.7 \%$ had paid work and $69 \%$ were economically dependent on another person [38]. Another study of hospital population in Argentina reported a delay of 12 months from first symptoms to a consultation with a rheumatologist [39].

With regard to the public awareness concerning RA, in Argentina, a representative study of the general population from different areas of the country $(n=24,324)$ revealed that $29 \%$ did not know that rheumatic diseases could affect children and young people, and $19 \%$ did not know that these diseases could cause deformities and disabilities [40].

\section{Discussion}

The help-seeking process of RA poses important challenges: illness is more than the clinical manifestations of the disease and the response to illness is a socially constructed process coherent with the meanings that the patient and his context give to the symptoms experience. The knowledge about the symptoms as perceived by the patients is still insufficient. The illness has also been reduced to the symptoms alone and not to the whole illness experience within their sociocultural contexts [41].

The trajectories and the health service utilization pathways are linked to the specific characteristics of the health and social systems that go from the micro to the macro level determinants. Hence, the theoretical framework that we propose here has to be understood in the light of each context and must also take into account the individual characteristics of each patient and his/her disease onset and evolution, i.e., the illness trajectory. One of the more relevant limitations that the illness trajectory concept has had on medical care utilization research on RA is that "the illness trajectory concept has the value of analytically ordering the events that occur over a sickness episode...but it cannot explain the link between such events" [21]. It is not only that social interaction has a descriptive important influence on the help-seeking process that will eventually lead to a diagnosis but they can also explain why this happens.

It has been reported that individuals with RA have little knowledge of the disease and resort to their immediate social 


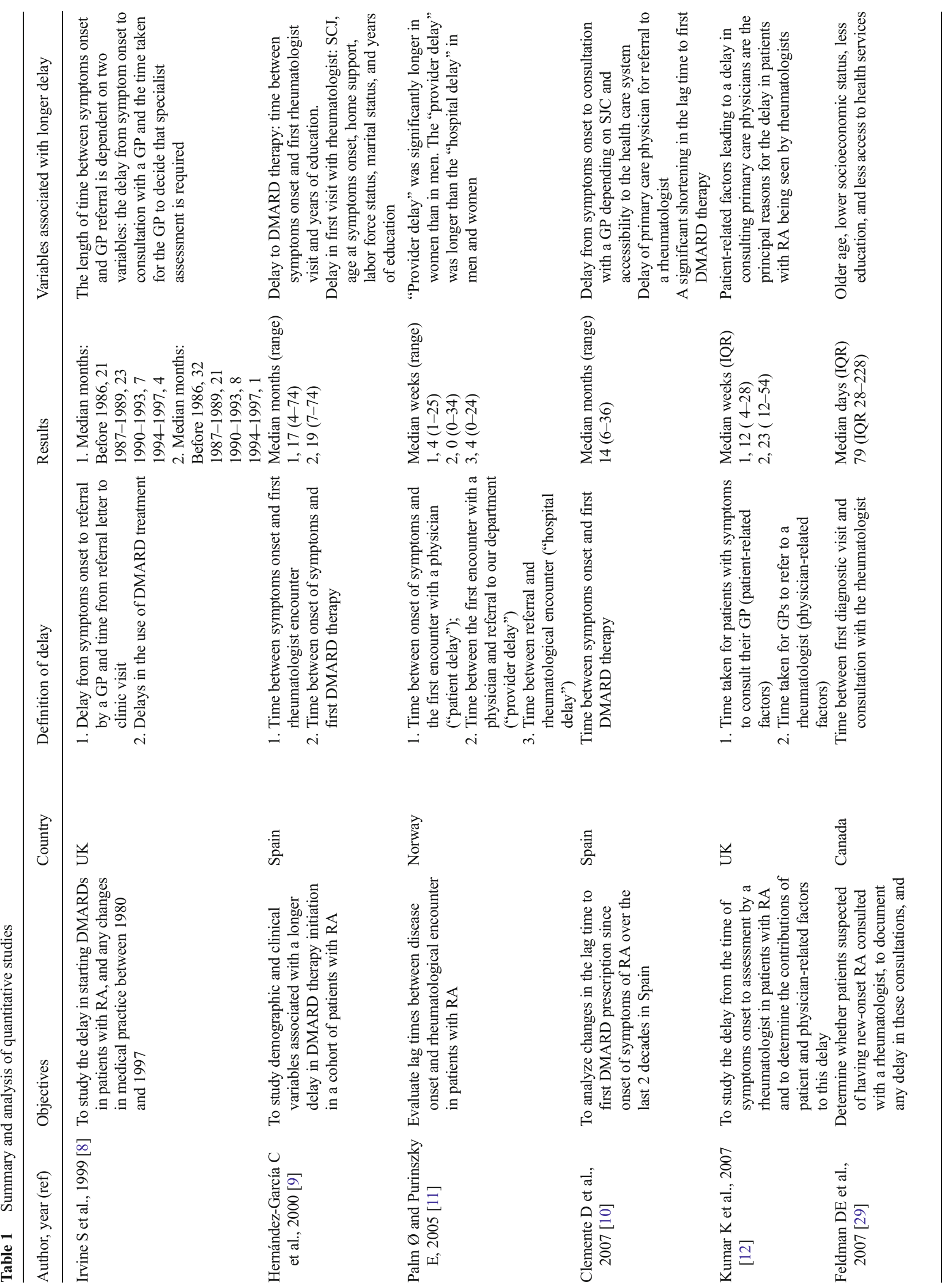




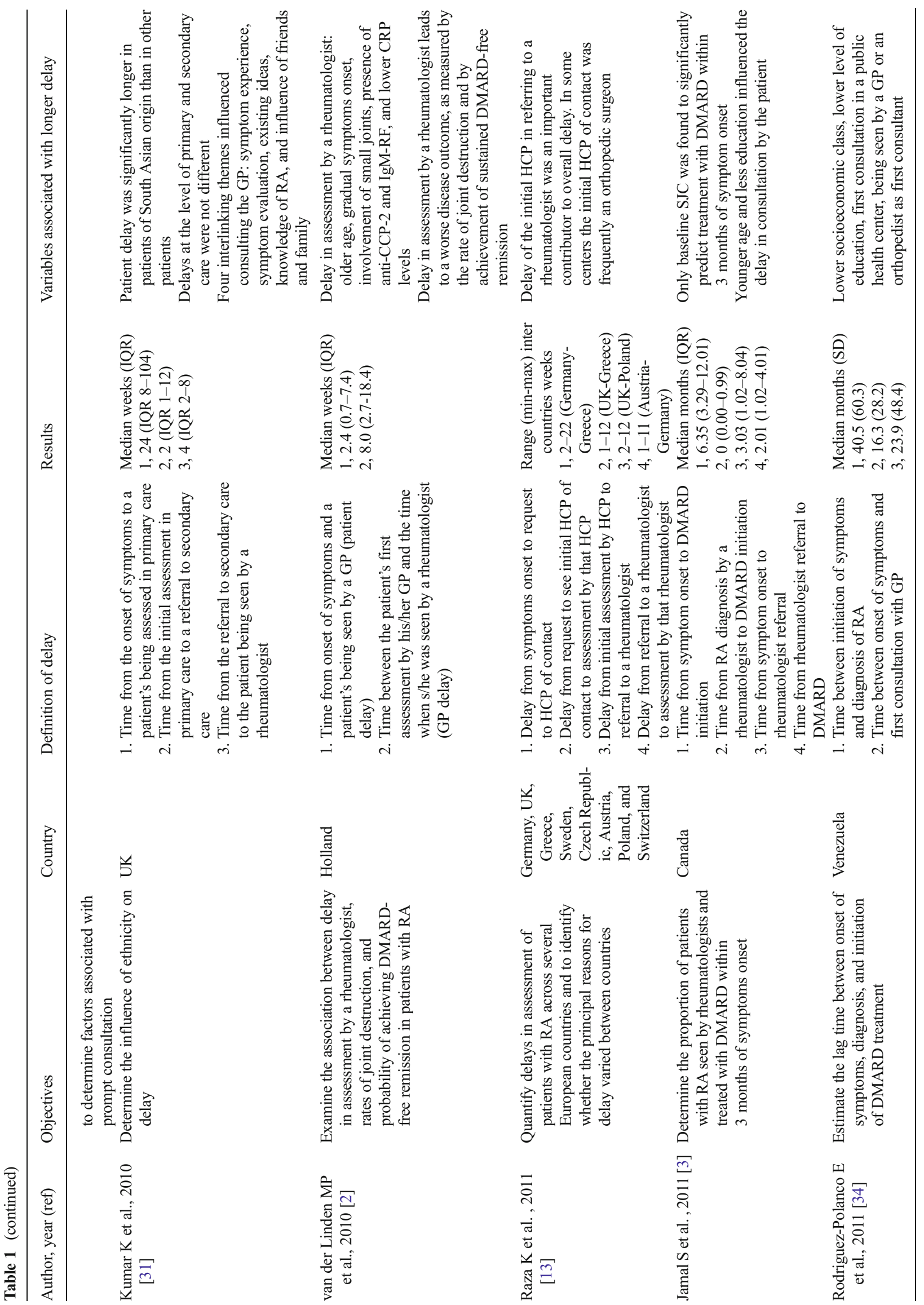




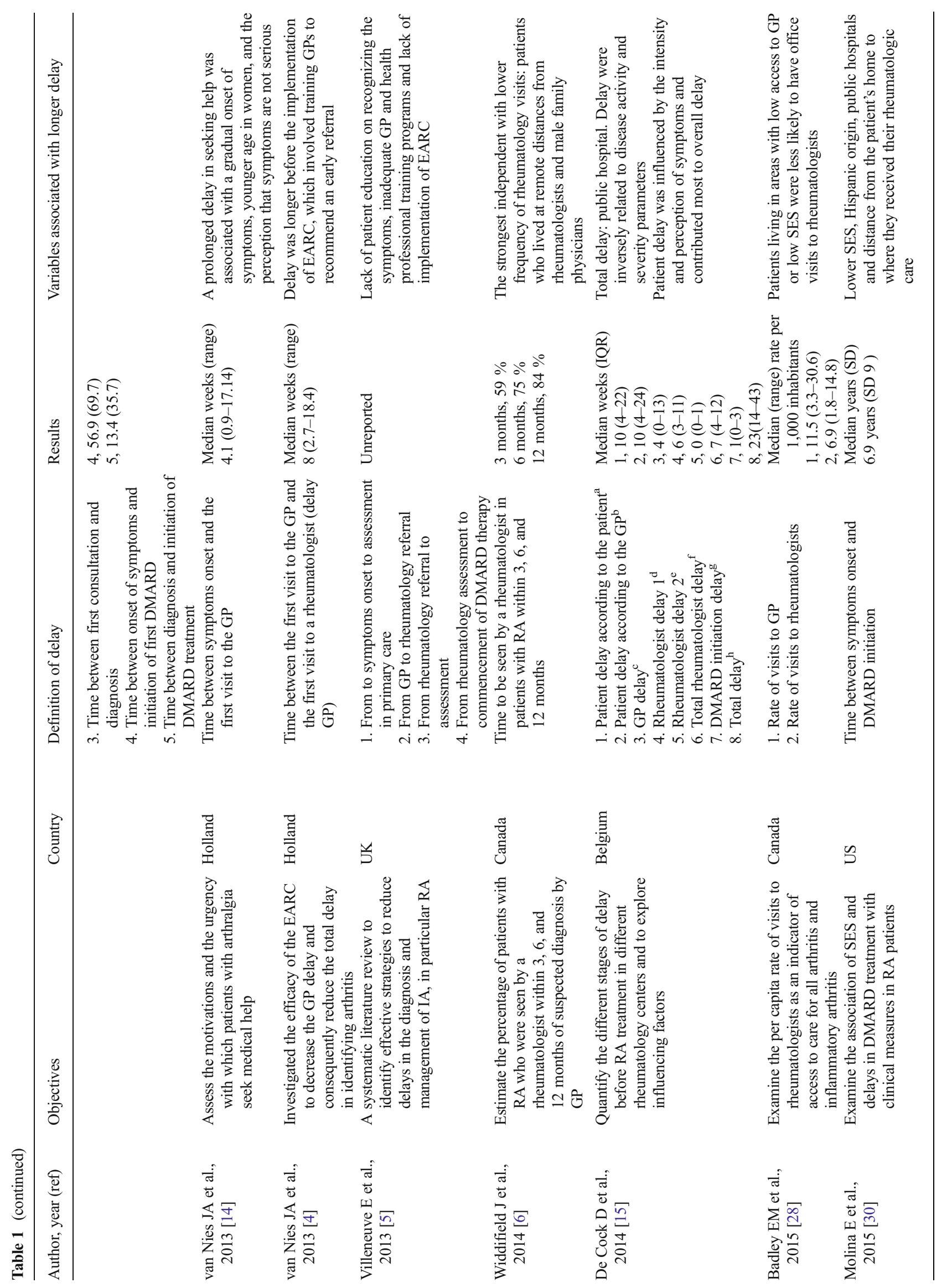


network to get information and help [24]. This is in line with the results of the Argentinean survey and the English study, which describe a limited knowledge of the rheumatic diseases $[27,40]$. The social network members do not always give support or speed up medical care but extend the time to seek medical help. On one hand, in RA, rapid onset episodes or the presence of severe or disabling symptoms activate prompt help-seeking both from the network and from the doctor [24]. Similar to many other studies, the role of social factors as mediators of medical help-seeking decreases with extreme situations: symptom severity and disabling progression [42]. On the other hand, Kumar et al. found that compared with British patients, the South Asian social networks delayed RA patients' medical attention because the latter extensively discussed their problem with their family and friends from both, the UK and from their native countries. This patients and social network behavior is not surprising as they belong to a collectivist culture whereas England is an individualistic society [31].

\section{Model of help-seeking process in RA in LA}

The results of our review show that in RA medical care utilization research, the theories and measurements of the constructs of illness trajectories, help-seeking, and accessibility are not integrated. Clinical and biomedical research has produced an important body of knowledge about the ideal medical treatment of RA, especially when the disease is identified early. However, medical treatment of RA involves the contact between the individuals and the health services and thus their study requires theories and frameworks that allow for the understanding of these relationships as complex social phenomena. Many of the social and contextual aspects have been studied with isolated traditional social variables that are only the tip of the iceberg of complex social realities that need to be considered and connected. There is a need of a multilevel perspective (e.g., the individuals, the social environment, the health system), together with the examination of the links between the different levels and dimensions of the problem. Many aspects of the illness experience, of the help-seeking process, and of access and delay of RA medical care have been studied, but it is not easy to locate or to explain the research problems and the different results obtained within a broad theoretical frame of reference. Furthermore, the concept of RA help-seeking is frequently used as a synonym of medical help-seeking. This is an example of the conceptual confusions due to the lack of clarity of the theories underlying health services utilization and medical care research.

The research in RA medical care utilization in different contexts other than very few European countries and Canada is almost nonexistent. Most of the literature covers the study of the medical care service utilization of RA patients in countries with universal public health care systems that covers all 
population. Problems such as health care inequity and cultural competence, availability, affordability, and accessibility of primary care physicians and specialists have not been specifically studied within a comprehensive health service framework. They do not seem to be relevant problems in the research agenda. However, for most of developing countries, this needs to be a priority. They have a completely different social context and most of the health services are insufficient, inaccessible, fragmented, limited, and inequitable in both quantity and quality. If research on RA service utilization is to be undertaken in these countries, there is a need for a comprehensive conceptual framework than can enable researchers to integrate the study of the problems within broad theoretical and methodological perspectives.

In order to have a more clear perspective of the problems that fall under the broad concept of health service utilization of RA patients, we propose a conceptual framework that graphically synthesizes the intersection between the help-seeking processes and the domains of the concept of accessibility (Fig. 3). There is much confusion between these two concepts mostly because they partly overlap in a time sequence and because they are commonly used in two fields with their own definitions: the social sciences and health service research.

On the one hand, the concept of accessibility (or access) is restricted to formal health services and pertains to the field of health services utilization. Under a broad perspective, Donabedian [43] includes service accessibility as part of quality of health care. On the other hand, the notion of helpseeking belongs to the social sciences and covers all stages and process of seeking any kind of help useful to meet the health needs [43]. However, this process has a sequence in time and is dynamic in nature as many elements interact simultaneously (e.g., symptom perception, individual behavior, and family advice).

The two main phases of the help-seeking process are depicted at the top of the diagram: the pre-patient and the patient phase. The characteristics of the population are at the left side and those of the health services are at the right. The domains of health service accessibility are specified at the right side and comprises the three (not strictly) sequential aspects of accessibility: geographical, economic (costs), and organizational accessibility. The latter is subdivided into two: the entry process and the continuity of care. As the patient phase includes what happens from the initial contact with the health services, the accessibility problems coincide with the second part of the help-seeking, namely medical care helpseeking.

Following McKinlay [42], the pre-patient phase comprises the range of behavior and contacts that occur prior to encountering professional, formal health care. Hence, the notion of help-seeking does not stop or start at the entrance to

Conceptual framework of the intersection between the help-seeking processes and the domains of accessibility

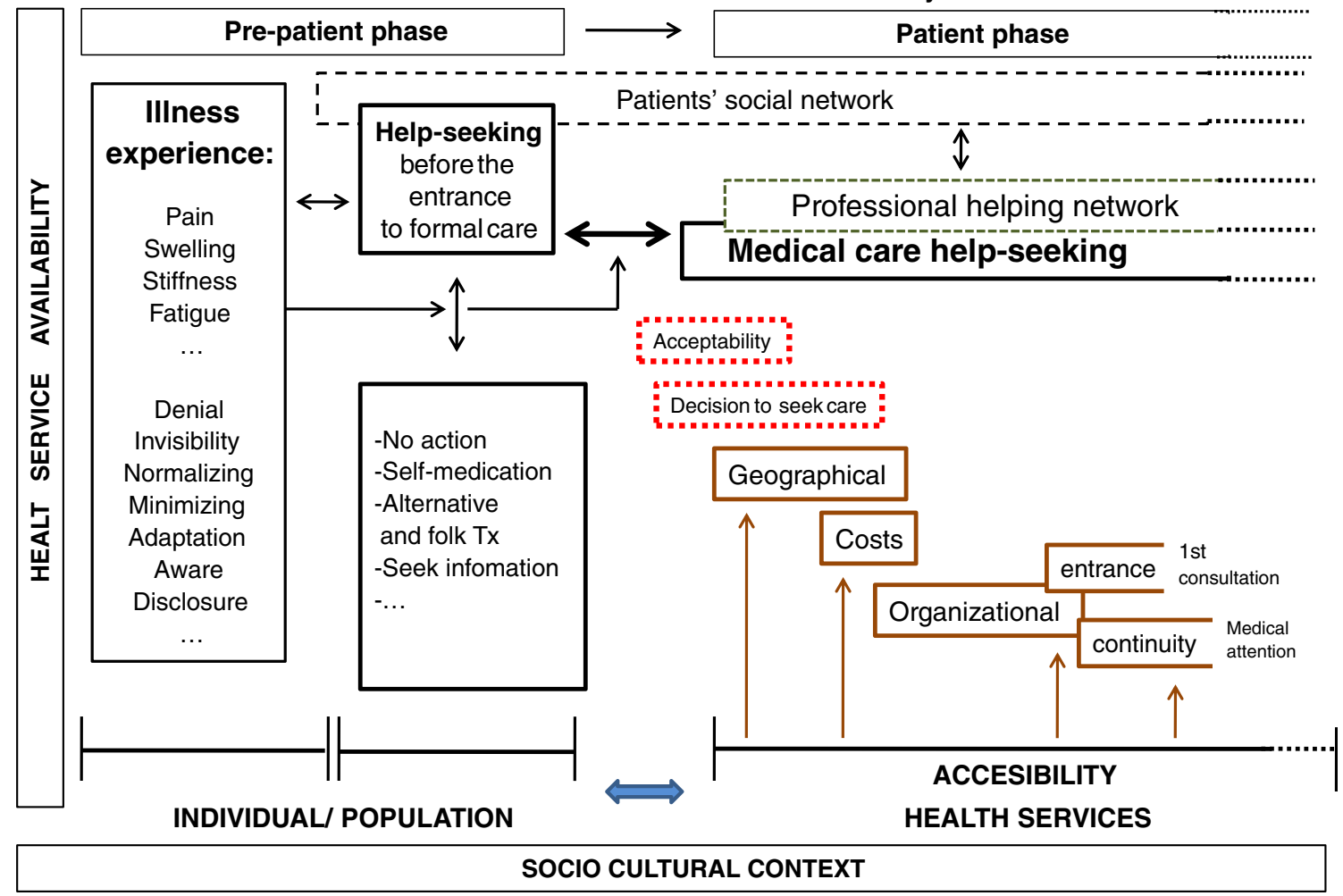

Fig. 3 Conceptual framework of the intersection between the help-seeking processes and the domains of accessibility 
professional health services and it is not restricted neither to formal nor medical health services, as it is commonly assumed. In fact, as shown in Fig. 2, the transition from the pre-patient phase to the patient phase is an important step in help-seeking because it is the point at which the two different social networks get together. Then the professional helping network begins to exert greater social control than the social network. The notion of "social network" refers to "that set of contacts with relatives, friends, neighbors, etc., through which individuals maintain a social identity and receive emotional support, material aid, services and information and develop social contacts." The functions of the "social network" activated by the illness experience do not stop after medical care starts, as it is part of the broader permanent web of interpersonal relations and social capital of the individual.

Access is not synonym of availability or use of services. The latter is the evidence of access, and availability is the mere existence of the service. Health service availability placed at the left side is the first element of medical help-seeking and of accessibility to formal health services. Accessibility is placed at the second half of the figure, as it is the result of the degree of fit between the characteristics of the individual or population and those of the health services [43].

After the individual decides to ask for available medical care, he faces geographical accessibility problems because $\mathrm{s} / \mathrm{he}$ has to be able to travel and has to have the means to do it. The next type of accessibility to be faced are all types of costs (monetary and opportunity cost): problems such as transportation, medical fees, waiting times, service interruptions, medicines, lab tests, time out of work (e.g., younger population faces longer delays to specialized RA care because they might have less time than the retired or the elderly to seek medical care) [43]. The components of the organizational accessibility are the entry to the system (e.g., if they struggle to get an appointment or they have to wait long between they are given an appointment and the appointment itself) and the continuity of care, i.e. subsequent service utilization.

We propose this conceptual integrated framework for the study of RA in order to join the elements of the pre-patient help-seeking to the medical care help-seeking (or patient phase) together with the specification of the different types of accessibility problems of the social and health services contexts. However, this framework can also be used for any other type of rheumatologic diseases or can be linked to other diseases such as cancer $[44,45]$. The experience of chronicity in rheumatologic diseases also needs to be considered. Chronicity can be seen as an irreversible event in the experience of a disease. A relationship between time and discomfort, without the chance of going back to the previous stages of life, foments irreversibility, which is experienced with anguish and sadness. Suffering becomes part of the patient.

The cultural context of this model should also be considered before implementation. This requires incorporating elements such as medical pluralism, which refers to the mix of health care systems with the processes that the individuals undergo to attend their discomfort or suffering. The combination or use of different care systems allows individuals to cover the diverse expressions of their illness, which vary according to many factors such as severity or chronicity.

The study about the problems for the ideal medical care utilization for RA is also a challenge because it is located at the intersection of clinical, sociomedical, epidemiological, and health care research. Research efforts are needed to analyze and integrate the accumulated knowledge on this subject, to facilitate the understanding of a comprehensive perspective of this phenomenon, and for the identification of the research areas that are needed in order to improve the response of health care services to RA patients needs.

Open Access This article is distributed under the terms of the Creative Commons Attribution 4.0 International License (http://creativecommons.org/licenses/by/4.0/), which permits unrestricted use, distribution, and reproduction in any medium, provided you give appropriate credit to the original author(s) and the source, provide a link to the Creative Commons license, and indicate if changes were made.

\section{References}

1. Raza K (2010) The Michael Mason prize: early rheumatoid arthritis - the window narrows. Rheumatology (Oxford) 49:406-410. doi:10.1093/rheumatology/kep392

2. van der Linden MP, le Cessie S, Raza K et al (2010) Long-term impact of delay in assessment of patients with early arthritis. Arthritis Rheum 62:3537-3546

3. Jamal S, Alibhai SM, Badley EM et al (2011) Time to treatment for new patients with rheumatoid arthritis in a major metropolitan city. J Rheumatol 38:1282-1288. doi:10.1002/art.27692

4. van Nies JA, Brouwer E, van Gaalen FA et al (2013) Improved early identification of arthritis: evaluating the efficacy of early arthritis recognition clinics. Ann Rheum Dis 72:1295-1301. doi:10. 1136/annrheumdis-2012-202289

5. Villeneuve E, Nam JL, Bell MJ et al (2013) A systematic literature review of strategies promoting early referral and reducing delays in the diagnosis and management of inflammatory arthritis. Ann Rheum Dis 72:13-22. doi:10.1136/annrheumdis-2011-201063

6. Widdifield J, Paterson JM, Bernatsky S, et al. (2014) Access to rheumatologists among patients with newly diagnosed rheumatoid arthritis in a Canadian universal public healthcare system. BMJ Open 31;4 (1):e003888. doi: 10.1136/bmjopen-2013-003888

7. Sørensen J, Hetland ML (2015) Diagnostic delay in patients with rheumatoid arthritis, psoriatic arthritis and ankylosing spondylitis: results from the Danish nationwide DANBIO registry. Ann Rheum Dis 74(3), e12. doi:10.1136/annrheumdis-2013-204867

8. Irvine S, Munro R, Porter D (1999) Early referral, diagnosis, and treatment of rheumatoid arthritis: evidence for changing medical practice. Ann Rheum Dis 58:510-513

9. Hernández-García C, Vargas E, Abásolo L et al (2000) Lag time between onset of symptoms and access to rheumatology care and DMARD therapy in a cohort of patients with rheumatoid arthritis. J Rheumatol 27:2323-2328 
10. Clemente D, Hernández-García C, Abásolo L et al (2007) Reduction in time until first treatment with disease modifying treatment in patients with rheumatoid arthritis. Reumatol Clin 3:24550. doi:10.1016/S1699-258X(07)73698-7

11. Palm Ø, Purinszky E (2005) Women with early rheumatoid arthritis are referred later than men. Ann Rheum Dis 64:1227-1228

12. Kumar K, Daley E, Carruthers DM et al (2007) Delay in presentation to primary care physicians is the main reason why patients with rheumatoid arthritis are seen late by rheumatologists. Rheumatology (Oxford) 46:1438-1440

13. Raza K, Stack R, Kumar K et al (2011) Delays in assessment of patients with rheumatoid arthritis: variations across. Eur Ann Rheum Dis 70(10):1822-1825. doi:10.1136/ard.2011.151902

14. van Nies JA, Brouwer E, de Rooy DP et al (2013) Reasons for medical help-seeking behaviour of patients with recent-onset arthralgia. Ann Rheum Dis 72:1302-1307. doi:10.1136/ annrheumdis-2012-201995

15. De Cock D, Meyfroidt S, Joly J et al (2014) A detailed analysis of treatment delay from the onset of symptoms in early rheumatoid arthritis patients. Scand J Rheumatol 43:1-8. doi:10.3109/ 03009742.2013.805242

16. McKinlay J (1985) Social network influences on morbid episodes and the career of help seeking. In: Eisenberg L, Kleinman L (eds) The relevance of social science for medicine. Reidol, Dordrecht, $\mathrm{p}$ 78

17. Pelaez-Ballestas I, Perez-Taylor R, Aceves - Avila JF et al (2013) 'Not-Belonging': illness narratives of Mexican patients with ankylosing spondylitis. Med Anthropol 32:487-500. doi:10.1080/ 01459740.2012 .716883

18. Kleinman A (1988) Illness narratives. Suffering, healing and the human condition. Basic Books, USA

19. Kleinman A (1980) Patients and healers in the context of culture. An explanation of the borderland between anthropology, medicine and psychiatry. University of California Press, Berkeley, USA

20. Stauss AL, Glaser BG (1975) Chronic illness and the quality of life. Mosby, Saint Louis, USA

21. Allen D, Griffiiths L, Lyne P (2004) Understanding complex trajectories in health and social care provision. Sociol Health Illn 26: $1008-1030$

22. Greenhalgh T (2004) Meta-narrative mapping: a new approach to the systematic review of complex evidence. In: Hurwitz B, Greenhalgh T, Vieda S (eds) Narrative research in health and illness. BMJ Book-Blackwell, London

23. Sheppard J, Kumar K, Buckley CD et al (2008) 'I just thought it was normal aches and pains': a qualitative study of decisionmaking processes in patients with early rheumatoid arthritis. Rheumatology (Oxford) 47:1577-1582. doi:10.1093/ rheumatology/ken304

24. Stack RJ, Shaw K, Mallen C et al (2012) Delays in help seeking at the onset of the symptoms of rheumatoid arthritis: a systematic synthesis of qualitative literature. Ann Rheum Dis 71:493-497. doi:10.1136/ard.2011.155416

25. Stack RJ, Sahni M, Mallen CD et al (2013) Symptom complexes at the earliest phases of rheumatoid arthritis: a synthesis of the qualitative literature. Arthritis Care Res 65:1916-1926. doi:10.1002/acr. 22097

26. McDonald HN, Dietrich T, Townsend A et al (2012) Exploring occupational disruption among women after onset of rheumatoid arthritis. Arthritis Care Res 64:197-205. doi:10.1002/acr.20668

27. Simons G, Mallen CD, Kumar K, et al (2015) A qualitative investigation of the barriers to help-seeking among members of the public presented with symptoms of new-onset rheumatoid arthritis. J Rheumatol Feb 1. pii: jrheum.140913

28. Badley EM, Canizares M, Gunz AC et al (2015) Visits to rheumatologists for arthritis: the role of access to primary care physicians, geographic availability of rheumatologists, and socioeconomic status. Arthritis Care Res 67:230-239. doi:10.1002/acr.22413

29. Feldman DE, Bernatsky S, Haggerty J et al (2007) Delay in consultation with specialists for persons with suspected new-onset rheumatoid arthritis: a population-based study. Arthritis Rheum 57:1419-1425

30. Molina E, del Rincon I, Restrepo JF, et al (2015) Association of socioeconomic status with treatment delays, disease activity, joint damage and disability in rheumatoid arthritis. Arthritis Care Res (Hoboken). doi: 10.1002/acr.22542

31. Kumar K, Daley E, Khattak F et al (2010) The influence of ethnicity on the extent of, and reasons underlying, delay in general practitioner consultation in patients with RA. Rheumatology (Oxford) 49:1005-1012. doi:10.1093/rheumatology/keq011

32. Rat AC, Henegariu V, Boissier MC (2004) Do primary care physicians have a place in the management of rheumatoid arthritis? Joint Bone Spine 71:190-197

33. Gamez-Nava JI, Gonzalez-Lopez L, Davis P et al (1998) Referral and diagnosis of common rheumatic diseases by primary care physicians. Br J Rheumatol 37:1215-1219

34. Rodríguez-Polanco E, Al Snih S, Kuo YF et al (2011) Lag time between onset of symptoms and diagnosis in Venezuelan patients with rheumatoid arthritis. Rheumatol Int 31:657-665. doi:10.1007/ s00296-009-1358-9

35. Massardo L, Aguirre V, García ME et al (1995) Clinical expression of rheumatoid arthritis in Chilean patients. Semin Arthritis Rheum 25:203-213

36. Acevedo-Vásquez EM (2012) Some aspects of rheumatoid arthritis in Peru. Rev Soc Peru Med Interna Vol 25:1

37. Kaliski S, Bustos L, Artigas C et al (2001) Rheumatoid arthritis among Mapuche aborigines. A 16 years experience in the IX Region of the Chile. Rev Med Chil 129:253-258

38. Mussano E, Missakian S, Onetti CM (2007) Estudio demográficosocial de pacientes con artritis reumatoidea en la provincia de Córdoba (Argentina). Rev Argent Reumatol 4:13-22

39. Correa MDLA, Lencina V, Chaparro del Moral R et al (2012) Impacto de las guías de práctica clínica para el tratamiento de la artritis reumatoidea. Rev Argent Reumatol 23:18-23

40. $1^{\text {a }}$ Campaña federal de difusión de las enfermedades reumáticas. IOP Publishing PhysicsWeb.http://www.reumaquiensos.org.ar/ index.php/campanias. Accessed 10 Feb 2015

41. Andersen RS, Risør MB (2014) The importance of contextualization. Anthropological reflections on descriptive analysis, its limitations and implications. Anthropol Med 21:345-356

42. McKinlay J (1985) Social network influences on morbid episodes and the career of help seeking. In: Eisenberg L, Kleinman L (eds) The relevance of social science for medicine. Reidol, Dordrecht, $p$ 79

43. Donabedian A (1973) Aspects of medical care administration. Harvard University Press, Cambridge, MA

44. Unger-Saldaña K, Infante-Castañeda C (2011) Breast cancer delay: a grounded model of help-seeking behavior. Soc Sci Med 72:10961104. doi:10.1016/j.socscimed.2011.01.022

45. Unger-Saldaña K, Pelaez-Ballestas I, Infante- Castañeda C (2012) Development and validation of a questionnaire to assess delay in treatment for breast cancer. BMC Cancer 12:626. doi:10.1186/ 1471-2407-12-626 